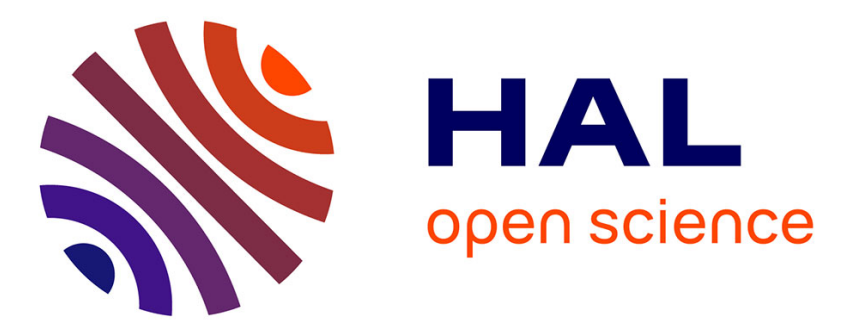

\title{
Carbon dioxide, argon, nitrogen and methane clathrate hydrates: Thermodynamic modelling, investigation of their stability in Martian atmospheric conditions and variability of methane trapping
}

Jean-Michel Herri, Eric Chassefière

\section{To cite this version:}

Jean-Michel Herri, Eric Chassefière. Carbon dioxide, argon, nitrogen and methane clathrate hydrates: Thermodynamic modelling, investigation of their stability in Martian atmospheric conditions and variability of methane trapping. Planetary and Space Science, 2012, 73 (1), pp.376-386. 10.1016/j.pss.2012.07.028 . hal-00760636

\section{HAL Id: hal-00760636 \\ https://hal.science/hal-00760636}

Submitted on 4 Dec 2012

HAL is a multi-disciplinary open access archive for the deposit and dissemination of scientific research documents, whether they are published or not. The documents may come from teaching and research institutions in France or abroad, or from public or private research centers.
L'archive ouverte pluridisciplinaire HAL, est destinée au dépôt et à la diffusion de documents scientifiques de niveau recherche, publiés ou non, émanant des établissements d'enseignement et de recherche français ou étrangers, des laboratoires publics ou privés. 
6

Carbon dioxide, argon, nitrogen and methane clathrate hydrates: thermodynamic modelling, investigation of their stability in Martian atmospheric conditions and variability of methane trapping

\author{
Jean-Michel Herri ${ }^{1}$, Eric Chassefière ${ }^{2,3}$
}

(1)

1 École Nationale Supérieure des Mines de Saint-Étienne, SPIN-EMSE, CNRS : FRE3312,

Laboratoire des Procédés en Milieux Granulaires, 158 Cours Fauriel, F-42023 Saint-Étienne

${ }^{2}$ Université Paris-Sud, Laboratoire IDES, UMR8148, Bât. 504, Orsay, F-91405, France;

${ }^{3}$ CNRS, Orsay, F-91405, France.

(1)

Submitted to Planetary and Space Sciences, December ?? 2011

13

(4)

\title{
Corresponding author
}

Jean-Michel Herri

Centre SPIN, École Nationale Supérieure des Mines de Saint-Étienne, 158 cours Fauriel, 42023

Saint-Étienne, France

Phone: +33(0)4 77420292

Fax : +33(0)4 77429694

E-mail: $\underline{\text { herri@emse.fr }}$ 


\section{$1 \quad$ Abstract}

2

3 This paper deals with the stability of clahtrate hydrates at low temperature and low pressure in the 4 conditions prevailing in the atmosphere and at the surface of Mars. We fit the classical van der

5 Waals model to compare deviation from experimental results published in the literature. It appears

6 to be acceptable and allows to simulating a Martian gas, $\mathrm{CO}_{2}$ dominated (95.3\%) plus nitrogen

7 (2.7\%) and argon (2\%). The hydrate is a $\mathrm{CO}_{2}$-based hydrate which is unstable during Mars'

8 summer and stable during Mars' winter. The proportion of methane in the hydrate is estimated and

9 is found to be from one tenth to one third of the composition of the gas phase. The proportion

10 depends on the crystallographic structure which is assumed to be formed. In fact, both the structure

11 I and II appear to be stable in the conditions of Mars' winter. The consequences of these results on

12 our understanding of the atmospheric cycle of Martian methane are drawn and analyzed. We propose upper limits on (i) the seasonal variation of methane due to a hypothesized alternate

14 formation of $\mathrm{CO}_{2} / \mathrm{N}_{2} / \mathrm{Ar} / \mathrm{CH}_{4}$ hydrates on the seasonal polar caps, and (ii) on the lifetime of atmospheric methane with respect to an hypothesized continuous trapping under hydrate form on the south polar cap. We show that these mechanisms have only small effects, and cannot play a significant role in the dynamics of methane in present Mars'atmosphere. Hypothesized clathrate hydrates trapped in the permanent south polar cap could include methane in relative proportions between 0.1 and 0.4 times the average global atmospheric ratio. Searching for the spectral signatures of clathrate hydrates on the caps and, if detectable, of inhomogeneities of the $\mathrm{CH}_{4}$ mixing ratio in possible local atmospheric plumes forming during the sublimation of polar hydrate pockets in spectroscopic data from existing (Mars Express, MRO) and future (TGO-Exomars) missions is an interesting challenge of Mars science and astrobiology. 
1 Keywords: Mars, clathrate hydrate, nitrogen, carbon dioxide, argon, methane, equilibrium 


\section{Introduction}

Methane has been detected in Mars' atmosphere from both Earth and orbital probes (Mars Express, Mars Global Surveyor) at an average 10-20 ppb level (Krasnopolsky et al., 2004; Formisano et al., 2004; Mumma et al., 2009; Fonti and Marzo, 2010; Geminale et al., 2011). One of the most striking characteristics of the observed $\mathrm{CH}_{4}$ is its high temporal and spatial variability, implying a lifetime of 200 days (Lefèvre and Forget, 2009), much shorter than the currently admitted value of $300 \mathrm{yr}$ based on existing photochemical models (see e. g. Krasnopolsky, 2006). The nature of $\mathrm{CH}_{4}$ sink is unknown. Spacecraft data (MGS, Mars-Express) which now span $\sim 6$ Martian years (MY24-MY29) and Earth-based measurements show a globally consistent and reproducible seasonal behavior of the $\mathrm{CH}_{4}$ mixing ratio, with definitely less $\mathrm{CH}_{4}$ in the atmosphere during northern winter. More generally, existing observations show that $\mathrm{CH}_{4}$ is spatially and temporally highly variable (Fonti and Marzo, 2010; Geminale et al., 2011). The origin or methane is not known. It could have been produced by hydrothermal processes in the crust (Oze and Sharma, 2005; Lyons et al., 2005), or possibly biogenically (Atreya et al., 2006), then stored in the cryosphere under the form of hydrates for long periods of time before being released to the atmosphere (Chassefière and Leblanc, 2011, Chastain and Chevrier, 2007). The space and time variability of atmospheric $\mathrm{CH}_{4}$ is still poorly understood. One possible explanation could be the erosion within the atmosphere of suspended metastable $\mathrm{CH}_{4}$ clathrate hydrate particles by condensation/sublimation processes (Chassefière, 2009). Adsorption in the regolith, although significant, has been shown to play a minor role in the $\mathrm{CH}_{4}$ seasonal variability (Meslin et al., 2011). Also none of the mechanisms presented has kinetics fast enough to explain the very rapid variations of methane in the atmosphere. 
The goal of the present paper is to investigate the possible contribution of an hypothesized alternate $\mathrm{CO}_{2} / \mathrm{N}_{2} / \mathrm{Ar} / \mathrm{CH}_{4}$ clathrate hydrate formation cycle, resulting from the alternate condensation of $\mathrm{CO}_{2}$ and $\mathrm{H}_{2} \mathrm{O}$ on seasonal hemispheric polar caps, on the seasonal cycle of $\mathrm{CH}_{4}$. A model of the (Pressure-Temperature) equilibrium of clathrate hydrates in the atmosphere of Mars is presented. Following the contributions of Chastain and Chevrier (2007) and Thomas et al. (2009), we applied a model based on the approach of van der Waals and Platteeuw (1959). Chastain and Chevrier (2007) and Thomas et al. (2009) have simulated the equilibrium conditions of hydrate stability in Martian conditions by extrapolating the model to very low temperature. Our contribution is to validate this extrapolation by comparing the model to experimental data at low temperature. We point the necessity to modify the internal parameters, and especially the Kihara parameters. Our contribution strengthens the conclusion of Chastain and Chevrier (2007) about the stability of gas hydrate on Mars. We conclude also that gases are fractionated from atmosphere to hydrate with fractionation factors similar to the ones proposed by Thomas et al. (2009).

For pure gases and in winter Martian conditions (temperature estimated in the range from 140-160 $\mathrm{K})$, the model reveals to fit experimental data in the range $140-273 \mathrm{~K}$ with a mean deviation of 4$20 \%$, depending on the gas. Then, modelling is applied to a gas which composition is that of the atmosphere of Mars. The hydrate appears to be a $\mathrm{CO}_{2}$-based hydrate which is stable at temperature below $150 \mathrm{~K}$ (Structure II being assumed to form) or $148.8 \mathrm{~K}$ (Stucture I being assumed to form). We have used a pressure at the surface of Mars of $0.6 \mathrm{kPa}$. The pressure of Mars' atmosphere seasonally varies in the range from 0.6 to $0.9 \mathrm{kPa}$. By using a slightly different value of $0.9 \mathrm{kPa}$ (Thomas et al, 2009), the hydrate is stable at temperature below $154 \mathrm{~K}$ (Structure I) or $156.8 \mathrm{~K}$ (Structure II). It results that the Martian gas hydrate is strongly suspected to be stable during the winter season. The proportion of methane in the hydrate is estimated and compared to the 
estimation performed by Thomas et al. (2009). The consequences of the results on the seasonal and long-term variability of atmospheric $\mathrm{CH}_{4}$ are presented and discussed.

\section{Modelling}

\section{Introduction}

The van der Waals and Platteeuw (1959) model describes the equilibrium of hydrate phases by means of a convergence between a statistical thermodynamics approach implementing Kihara parameters and a classical approach implementing reference state parameters. It is the most common model used because of its physical relevance and easy implementation in codes. In a recent publication (Herri et al, 2011), we have optimized the Kihara parameters versus the different sets of reference state parameters which are published in the literature (Dharmawardhana et al., 1980; John et al., 1985; Handa and Tse, 1986). The Kihara parameters have been optimized to fit equilibrium data concerning methane, carbon dioxide and nitrogen, taken as pure gases or in mixtures. Equilibrium data were not only classical (Pressure,Temperature) equilibrium curves but also the envelope curves for gases mixtures consisting in (Pressure, Temperature, gas composition, hydrate composition) equilibrium data. We observed the Handa and Tse (1986) reference state parameters to be the best to fit our data. In the following work, we use these reference state parameters to simulate hydrate equilibrium in Mars condition. In Herri et al (2011), the Kihara parameters have been optimized in (Pressure, Temperature) conditions for which we can get a maximum of experimental data from literature, obtained mainly at Earth's ambient temperature 273-293 K and pressures in the range from 1 to some tens MPa. The ambient Martian conditions are very different. Pressure varies over Mars surface from 0.3 to $1 \mathrm{kPa}$ depending on location and 
season. In winter period, on the southern permanent $\mathrm{CO}_{2}$ ice polar cap, the temperature can be as low as $148 \mathrm{~K}$ (temperature of $\mathrm{CO}_{2}$ condensation at $0.6 \mathrm{kPa}$ ) and even reach $143 \mathrm{~K}$ due to the high altitude of the top of the south polar cap. During the summer period, at low latitude and sunny time, temperature can reach $273 \mathrm{~K}$ exceptionally.

So, the possibility to extrapolate the van der Waals and Platteeuw models from Earth's conditions to Martian conditions needs to be carefully examined. In this paper, we validate the model against available data of pure gas hydrates in Martian conditions. We observe that the Kihara parameters need to be optimized again and are different from the ones optimized at positive temperature (Herri et al, 2011).

The composition of the Martian atmosphere is $\mathrm{CO}_{2}$ dominated (95.3\%) plus nitrogen (2.7\%) and Argon (2\%) and traces of other compounds: $\mathrm{O}_{2}(1200 \pm 100 \mathrm{ppm}), \mathrm{CO}(700 \pm 200 \mathrm{ppm}), \mathrm{H}_{2} \mathrm{O}$ ( $<1000 \mathrm{ppm}$ with an average at $200 \mathrm{ppm}), \mathrm{H}_{2}(20 \mathrm{ppm}), \mathrm{O}_{3}(<0.2 \mathrm{ppm})$ and $\mathrm{CH}_{4}(<50 \mathrm{ppb}$ with an average at $15 \mathrm{ppb}$ ) (Owen et al., 1977; Mumma et al., 2009) .

\section{Hydrate structure}

Three different structures have been identified : SI, SII and SH. They differ by their crystallographic structure in which water is organized in a three dimensional network. It liberates internal cavities of different polyhedral cavities called $5^{12}, 5^{12} 6^{2}, 5^{12} 6^{4}, 4^{3} 5^{6} 6^{3}$ and $5^{12} 6^{8}\left(e^{f}\right.$ describes a polyhedron: $e$ is the number of edges of the face, and $f$ is the number of faces with $e$ edge). In Table 1 are described more precisely the SI and SII structures, the only ones that can be formed due to the nature of the Martian gases. 


\section{Table 1}

\section{Modelling}

In the case of hydrates, in thermodynamic equilibrium, the equality of chemical potentials of water in the ice (or liquid) phase and in the hydrate phase can be written by introducing a reference state which is a hypothetical phase $\beta$ that corresponds to a hydrate with empty cavities.

$\Delta \mu_{\mathrm{w}}^{\mathrm{H}-\beta}=\Delta \mu_{\mathrm{w}}^{\mathrm{L}-\beta}$

Where $\Delta \mu_{\mathrm{w}}^{\mathrm{H}-\beta}$ and $\Delta \mu_{\mathrm{w}}^{\mathrm{L}-\beta}$ are the differences of the chemical potentials between water in hydrate or liquid phase and water in the reference phase, respectively.

Modelling of $\Delta \mu_{\mathrm{w}}^{\mathrm{H}-\beta}$

$\Delta \mu_{\mathrm{w}}^{\mathrm{H}-\beta}$ is then determined from statistical thermodynamics whereas $\Delta \mu_{\mathrm{w}}^{\mathrm{L}-\beta}$ is determined by means of relations from classical thermodynamics.

$\Delta \mu_{\mathrm{w}}^{\mathrm{H}-\beta}=R T \sum_{i} v_{i} \ln \left(1-\sum_{j} \theta_{j}^{i}\right)$

In Eq. (2) $v_{i}$ is the number of cavities of type $i$ per mole of water and $\theta_{j}^{i}$ is the occupancy factor $\left(\theta_{j}^{i} \in[0,1]\right)$ of the cavities of type $i$ by the gas molecule $j$. This last parameter is essential to define the thermodynamic equilibrium and to determine the hydrate properties. 
The occupancy factor is described by a model based on ideas considering the analogy between the gas adsorption in the 3-dimensional hydrate structure and the 2-dimensional Langmuir adsorption. It can be expressed as a function of the fugacity $f_{j}$ of the gas $j$ as:

$\Delta \mu_{\mathrm{w}}^{\mathrm{H}-\beta}=R T \sum_{i} v_{i} \ln \left(1-\sum_{j} C_{j}^{i} f_{j}(T, P)\right)$,

where $C_{j}^{i}$ is the Langmuir constant of component $j$ in the cavity $i$ that describes the interaction potential between the encaged guest molecule and the surrounding water molecules evaluated by assuming a spherically symmetrical cage that can be described by a spherical symmetrical potential:

$C_{j}^{i}=\frac{4 \pi}{k T} \int_{0}^{\infty} \exp \left(-\frac{w(r)}{k T}\right) r^{2} d r$

where $w$ is the interaction potential between the cavity and the gas molecule according to the distance $r$ between the guest molecule and the water molecules over the structure. The interaction potential can be determined by different models such as e.g. the van der Waals and Platteeuw model (1959), the Parrish and Prausnitz model (1972) or the so-called Kihara model. The latter, being the most precise (McKoy, 1963), can be expressed as:

$$
\begin{aligned}
& w(r)=2 z \varepsilon\left[\frac{\sigma^{12}}{\bar{R}^{11} r}\left(\delta^{10}+\frac{a}{\bar{R}} \delta^{11}\right)-\frac{\sigma^{6}}{\bar{R}^{5} r}\left(\delta^{4}+\frac{a}{\bar{R}} \delta^{5}\right)\right] \\
& \delta^{N}=\frac{1}{N}\left[(1-r / \bar{R}-a / \bar{R})^{-N}-(1+r / \bar{R}-a / \bar{R})^{-N}\right]
\end{aligned}
$$

The gas parameters $\varepsilon, \sigma$ and $a$ are the so-called Kihara parameters and can be calculated from experimental data by fitting the model equations to corresponding hydrate equilibrium 
experimental data. In this description, the interaction potential is only dependent on the properties of the gases (via the Kihara parameters), and on the geometrical properties of the cavities (through their coordination number $z$ and their average mean radius $\bar{R}$, see Table 2).

\section{Table 2}

Modelling of $\Delta \mu_{w}^{\varphi-\beta}$

The reference conditions are the temperature $T_{0}=273.15 \mathrm{~K}$ and the pressure $P_{0}=0$. The difference of the chemical potential of water between the reference phase (Ice in our case, but it could be liquid phase or vapour phase) and the (hypothetical) empty hydrate phase $\beta, \Delta \mu_{w}{ }^{\varphi-\beta}$, can be written as follows:

$$
\begin{aligned}
& \Delta \mu_{\mathrm{w}}^{\mathrm{L}-\beta}=T \frac{\left.\Delta \mu_{\mathrm{w}}^{\mathrm{L}-\beta}\right|_{T^{0}, P^{0}}}{T^{0}}-T \int_{T^{0}}^{T} \frac{\left.\Delta h_{\mathrm{w}}^{\mathrm{L}-\beta}\right|_{P^{0}}}{T^{2}} d T \\
& +\left.\int_{P^{0}}^{P} \Delta v_{\mathrm{w}}^{\mathrm{L}-\beta}\right|_{T} d P-\left.R T \ln a_{\mathrm{w}}^{\mathrm{L}}\right|_{T, P}
\end{aligned}
$$

The activity of water in the ice is 1 . If liquid water is present, $a_{\mathrm{w}}^{\mathrm{L}}$ is given as the product of the mole fraction of water in the liquid phase, $x_{w}$, and the activity coefficient of water in that phase, $\gamma_{\mathrm{w}}^{\mathrm{L}}$, hence $a_{\mathrm{w}}^{\mathrm{L}}=x_{\mathrm{w}} \gamma_{\mathrm{w}}^{\mathrm{L}}$. In a good approximation, the aqueous phase can be regarded as ideal and the activity coefficient therefore be set to a fixed value of 1 , resulting in $a_{\mathrm{w}}^{\mathrm{L}} \cong x_{\mathrm{w}}$. 
A refinement of the model is given by Sloan $(1998,2008)$ that takes into account the temperature dependence of the difference of molar enthalpy $\left.\Delta h_{\mathrm{w}}^{\mathrm{L}-\beta}\right|_{P^{0}}\left(\mathrm{~J} / \mathrm{mol} \mathrm{H}_{2} \mathrm{O}\right)$ using the well-known classical thermodynamic relationship

$\left.\Delta h_{\mathrm{w}}^{\mathrm{L}-\beta}\right|_{P^{0}}=\left.\Delta h_{\mathrm{w}}^{\mathrm{L}-\beta}\right|_{T^{0}, P^{0}}+\left.\int_{T^{0}}^{T} \Delta c_{p, \mathrm{w}}^{\mathrm{L}-\beta}\right|_{P^{0}} d T$

assuming a linear dependence of the difference of molar heat capacity $\left.\Delta c_{p, \mathrm{w}}^{\mathrm{L}-\beta}\right|_{P^{0}}\left(\mathrm{~J} / \mathrm{K} / \mathrm{mol} \mathrm{H}_{2} \mathrm{O}\right)$ on temperature according to :

$\left.\Delta c_{p, \mathrm{w}}^{\mathrm{L}-\beta}\right|_{P^{0}}=\left.\Delta c_{p, \mathrm{w}}^{\mathrm{L}-\beta}\right|_{T^{0}, P^{0}}+b_{p, \mathrm{w}}^{\mathrm{L}-\beta}\left(T-T^{0}\right)$

The values of the reference state parameters are given in Table 3.

\section{Table 3}

\section{Equilibrium}

Equilibrium is achieved as equality of $\Delta \mu_{\mathrm{w}}^{\mathrm{H}-\beta}=\Delta \mu_{\mathrm{w}}^{\mathrm{L}-\beta}$ is achieved.

A minimization algorithm has been implemented in GasHyDyn Sofware (Java language), to determine ( $\mathrm{P}, \mathrm{T}$, gas composition, hydrate composition) equilibrium from computing by using Kihara parameters and reference state parameters, or inversely, to determine parameters from (Pressure, Temperature, gas composition, hydrate composition) experimental data base (more details may be found in Herri et al, 2011). 
The procedure is the following. First, according to Mehta and Sloan (1996), the value of $a$ is fixed by using the correlation of Tee et al (1996). Then, for a given set of Kihara parameters $\varepsilon_{j}$ and $\sigma_{j}$, and a given temperature (resp. a given pressure), the calculated equilibrium pressure $P_{\text {calc }}$ (resp. the calculated equilibrium temperature $T_{\text {calc }}$ ) corresponds to the value such as $\Delta \mu_{\mathrm{w}}^{\mathrm{H}-\beta}=\Delta \mu_{\mathrm{w}}^{\mathrm{L}-\beta}$. Then the calculated pressure (resp. the calculated temperature) is compared to the experimental one $P_{\exp }$ (resp. $T_{\exp }$ ) and a deviation function can be defined as:

$$
F\left(\varepsilon_{j}, \sigma_{j}\right)=\sum_{l=1}^{N}\left|\frac{P_{\text {calc }}}{P_{\text {exp }}}-1\right| \rightarrow \min \left(\operatorname{resp} . F\left(\varepsilon_{j}, \sigma_{j}\right)=\sum_{l=1}^{N}\left|\frac{T_{\text {calc }}}{T_{\text {exp }}}-1\right| \rightarrow \min \right)
$$

In Eq. (10), the index $l$ assigns the specific data point and the summation has to be performed over all $N$ data of the set.

Kihara parameters given in Table 2 are optimized to minimize the error and fit the experimental results at low temperature implemented in the data base which is detailed below.

\section{Data Base}

The data base of GasHyDyn Sofware has been completed with the data at low temperature compiled in the review of Fray et al. (2010) concerning methane and $\mathrm{CO}_{2}$ clathrate below the ice points. Very few data can be found for $\mathrm{N}_{2}$ clathrate below the point, and in a very limited range of temperature of 261.7-270K (Mohammadi and Richon, 2010). For argon, few data has been found but in a wide range of temperature of 90 to $291 \mathrm{~K}$ in Holder et al., 1980 (original data from Saito and Kobayashi, 1965, and original data from Barrer and Edge, 1967). Data have been completed with the first two points of the history from de Forcrand (1923). 


\section{Comment on the geometric description of the cavity}

Theoretically, in equation 4 , the interaction potential $w(r)$ needs to be integrated from 0 to infinity. It means that the gas molecule interacts with the overall structure, not only with its first hydration shell (i.e. the water molecules of the cavity inside which the gas molecule is encapsulated), but also interacts with other molecules localized away from it. In fact, John and Holder (1982) have showed that $2^{\text {nd }}$ and $3^{\text {rd }}$ hydration shells contribute significantly to the Langmuir constant with a resulting change of this Langmuir constant by 1-2 orders of magnitudes (Sparks and Tester, J.W., 1992). Also, even with a rigorous integration of the interaction potential over all the hydration shells, the John and Holder model (1982) can give rigorous results only for spherical molecules (such has $\mathrm{Kr}, \mathrm{Ar}, \mathrm{CH}_{4} \ldots$ ). John et al (1985) have introduced a correction factor to take into account the asymmetry of the encapsulated molecules. All these refinement methods tend to give a physical signification to the interaction potential $w(r)$ and Kihara parameters but results in a time consuming calculation. For this reason, we have retained an integration of the cell potential over the first hydration shell.

\section{Comment on the reference properties}

Special attention has to be paid when assigning value for $\left.\Delta \mu_{\mathrm{w}}^{\mathrm{L}-\beta}\right|_{T^{0}, P^{0}}$ in Eq. (8) and $\left.\Delta h_{\mathrm{w}}^{\mathrm{L}-\beta}\right|_{T^{0}, P^{0}}$ in Eq. (7) since the corresponding data found in the literature vary strongly from one author to the other, mainly due to the difficulties arising when determining these quantities experimentally. The values can be found in the open literature as cited by Sloan $(1998,2007)$. However, in a previous work (Herri et al, 2010), we tested the different values in simulating the equilibrium conditions and composition of phases for gas hydrates formed from gas mixtures $\left(\mathrm{CO}_{2}-\mathrm{N}_{2}\right),\left(\mathrm{CO}_{2}-\mathrm{CH}_{4}\right)$ and $\left(\mathrm{CH}_{4}-\mathrm{N}_{2}\right)$ and liquid water. We observed the values of Handa and Tse (1986) to be the best ones. 


\section{Conclusion of comments}

In the end, the Kihara parameters remain adjustable parameters. As it has been claimed by John et al (1987) and reported by Mehta and Sloan (1996): the wrong kihara parameters, wrong cell potential, wrong Langmuir constants (and we can add from Herri et al (2010) the wrong reference parameters) could still lead to the right dissociation pressures.

\section{Simulation of Martian Hydrates}

The equilibrium is at first order governed by the dominating gas $\left(\mathrm{CO}_{2}, 95.7 \%\right)$ and secondly affected by second order constituents $\left(\mathrm{N}_{2}, 2.7 \%\right.$, and $\left.\mathrm{Ar}, 2 \%\right)$. It is not affected by very low concentration components such as $\mathrm{O}_{2}(1200 \pm 100 \mathrm{ppm}), \mathrm{CO}(700 \pm 200 \mathrm{ppm}), \mathrm{H}_{2} \mathrm{O}(<1000 \mathrm{ppm}$, with an average of $200 \mathrm{ppm}), \mathrm{H}_{2}(20 \mathrm{ppm}), \mathrm{O}_{3}(<0.2 \mathrm{ppm})$ and $\mathrm{CH}_{4}(<50 \mathrm{ppb}$ with an average of $15 \mathrm{ppb}$ ). Methane gas is a trace, but we will model it as precisely as possible because we want to understand its repartition between atmosphere and solid hydrate.

\section{Pure gas equilibrium in atmospheric Martian conditions}

Pure $\mathrm{CO}_{2}$ hydrates

Figure 1 plots the deviation between the experimental data and simulation depending on the values of $\varepsilon$ and $\sigma$. We compare 32 experimental results from Yasuda and Ohmura (2008), Adisasmito et al. (1991), Falabella (1975), Miller and Smythe (1970) which cover a range of temperature from $151.52 \mathrm{~K}$ to $282.9 \mathrm{~K}$ and a pressure range from $0.535 \mathrm{kPa}$ to $4370 \mathrm{kPa}$. In Figure 1 , we can see that 
the $\varepsilon$ and $\sigma$ values which minimize the deviation are located in a deep valley. The figure 2 plots the $\varepsilon$ and $\sigma$ values in the valley, and the corresponding deviation. The minimum deviation corresponds to values of $\varepsilon$ and $\sigma$ reported in Table 2 .

\section{Figure 1}

\section{Figure 2}

The Figure 3 shows the deviation from the model implemented with the values of $\varepsilon$ and $\sigma$ reported in Table 2. The experimental data cover a wide range of temperature, from $273 \mathrm{~K}$ down to $150 \mathrm{~K}$, i.e. down to Martian winter temperature. The model simulates both the structure I and II. At high temperature, the stable structure is sI. For example, at a temperature of $271 \mathrm{~K}$, the respective equilibrium pressure of sI and sII structures are 1.08 $\mathrm{MPa}$ and 1.38 $\mathrm{MPa}$. But at lower temperature, especially in the range of temperature pertaining to Mars' winter period, there is an inversion of the stability. At a pressure of $0.6 \mathrm{kPa}$, the respective equilibrium temperatures of the structures sI and sII are $150 \mathrm{~K}$ and $148.8 \mathrm{~K}$. Experimentally, the observed equilibrium temperature is $155 \mathrm{~K}$ (interpolated value from experimental data). It is the reason why Martian gas hydrate are suspected to be stable (Miller and Smythe, 1970)

\section{$\underline{\text { Figure } 3}$}

\section{Pure $\mathrm{CH}_{4}$ hydrate}

We optimised the kihara parameters from a set of 27 experimental results from Fray et al (2010), Yasuda and Ohmura (2008), Adisasmito et al. (1991) which cover a range of temperature from 145.75 to $286.4 \mathrm{~K}$ and a pressure range from $2.4 \mathrm{kPa}$ to $10570 \mathrm{kPa}$. The figure 4 plots the $\varepsilon$ and $\sigma$ values in the valley, and the corresponding deviation. The minimum deviation corresponds to values of $\varepsilon$ and $\sigma$ reported in Table 2 . 


\section{Figure 4}

Figure 5 shows the deviation from the model implemented with the values of $\varepsilon$ and $\sigma$ reported in Table 2. The experimental data covers a very wide range of temperature, from $273 \mathrm{~K}$ down to 80 $\mathrm{K}$. The model fits with data for temperature below the ice point and deviates as the temperature decreases. In the temperature range close to $148 \mathrm{~K}$, the model fits in between the data from Fray et al (2010) with an average deviation of 9.8\%, and the data of Falabella and Vanpee (1974) with an average deviation of $19.75 \%$. It must be said that the data sets from the two authors are significantly different, and that our model is in better agreement with the experimental corpus of Fray et al (2010).

\section{$\underline{\text { Figure } 5}$}

Pure Ar hydrate

Figure 4 plots experimental data, and simulation from GasHyDyn software with Kihara parameters from Table 2. Data are the results of Saito and Kobayashi (1965) which have be found in Holder et al (1980), data from Barrer et Edge (1967), de Forcrand (1923) and Mohammadi and Richon (2011). The data from von Stackelberg (1949) are not reported because they appear not to be correct (Mohammadi and Richon, 2011). They cover a range of temperature from $283 \mathrm{~K}$ down to $90 \mathrm{~K}$. The deviation of the model is very good down to $138.7 \mathrm{~K}$ with an average deviation of $2.59 \%$. At temperature of $133.2 \mathrm{~K}$, deviation remains acceptable (10.9\%) but diverges completely down to $115.9 \mathrm{~K}$. In Martian conditions (down to $140-150 \mathrm{~K}$ ), model and data are therefore in very good agreement. 


\section{Figure 6}

Pure $\mathrm{N}_{2}$ hydrate

In the literature, we can find one set of experimental data from Mohammadi and Richon (2010) and Kuhs et al (2000) at high temperature just under the ice formation conditions, and down to 250 $\mathrm{K}$ only. We added points at positive temperature to look at the model on the upper range of temperatures (from Jhaveri and Robinson, 1965). Model and data are plotted in Figure 3. The optimisation of the kihara parameters has been simplified because there is no data enough to distinguish the best value of $\varepsilon$ and $\sigma$. For example, with $\mathrm{CO}_{2}$ or $\mathrm{CH}_{4}$, it can be observed from figure 2 or figure 4 that the deviation from model and experiments presents a clear minimum. We can retain the value of $\varepsilon$ and at this minimum. But, for Nitrogen, there is no clear minimum. So, we retained the value of $\sigma$ from Herri and Kwaterski (2011) and we optimized only $\varepsilon$. The result is given in Table 2 .

The model fits pretty well with data of Jhaveri and Robinson (1965), above $0^{\circ} \mathrm{C}$, and Mohammadi and Richon (2000), below $0^{\circ} \mathrm{C}$. The change of the slope of the curve at the temperature of $0^{\circ} \mathrm{C}$ corresponds to a change of the phases in equilibrium. At positive temperature, the equilibrium is in between gas, liquid water and hydrate. Below $0^{\circ} \mathrm{C}$, the equilibrium is in between Ice, Hydrate and Gas. At lower temperature, the model deviates very rapidly from the data of Kuhs et al (2000). So, it is difficult to predict how the model will simulate the nitrogen equilibrium in Martian conditions around $148 \mathrm{~K}$. We need additional experimental data in Martian conditions to cross validate model and experiments. But we will see later that nitrogen only very slightly contributes to the stability of Martian hydrates in reason of a very poor integration in the hydrate structure. So, the precision of the model towards pure nitrogen hydrates is second order. 


\section{Figure 7}

\section{Intermediate conclusion}

From a comparison between data and model in the temperature range around $148 \mathrm{~K}$ (corresponding to Martian conditions during winter above $\mathrm{CO}_{2}$ ice caps), it can be seen that the model fits very well for argon and is acceptable for $\mathrm{CO}_{2}$ (mean deviation of $12 \%$ in the range [151.5-171.5K] for sI structure, and $7 \%$ for sII structure) from the data of Miller and Smythe (1970))

For pure methane hydrate, the model is between the data of Fray et al. (2010) and data Falabella and Vanpee (1974). From data of Fray et al. (2010), the model differs with a mean deviation of $25.7 \%$ at $145.8 \mathrm{~K}$. The model differs from the data of Falabella and Vanpee (1974) with a deviation of $26.5 \%$ at $148.8 \mathrm{~K}$ and $22.5 \%$ at $159.9 \mathrm{~K}$.

For $\mathrm{N}_{2}$, we didn't find low temperature data enough to validate the Kihara parameters at low temperature.

\section{Composite Martian hydrates}

3

4 We perform a simulation by assuming the presence of the dominating gases, only $\mathrm{CO}_{2}, \mathrm{~N}_{2}$ and Ar.

5 Table 4 shows the results of the simulation in the range 139-161 K. It reports equilibrium pressure 6 of Structure I and Structure II hydrates. We can see that Structure II is the most stable structure to 
7 be formed. The table 4 reports also the equilibrium pressure of pure $\mathrm{CO}_{2}$ hydrate. We can see that 8 the mixture on Mars with $2.7 \%$ of $\mathrm{N}_{2}$ and $2 \%$ of Ar gives a less stable hydrate which shifts the 9 equilibrium temperature, in a negligible manner. Secondly, if we look at the composition of the hydrate phase, we can observe that the hydrate is practically one hundred percent $\mathrm{CO}_{2}$ hydrate with traces of nitrogen and argon. So, the chemical influence of secondary gases such as nitrogen and argon is negligible because they do not participate in the structure. The shift in the equilibrium temperature of Martian gas hydrates $\left(\mathrm{CO}_{2}\right.$ dominated but with $5 \%$ of other gases $)$ is principally due to a decrease of the partial pressure of $\mathrm{CO}_{2}$.

(1)

\section{Table 4}

Also, we can state that the equilibrium cannot be affected by the tertiary gases, at very low concentrations, such as $\mathrm{O}_{2}(1200 \pm 100 \mathrm{ppm}), \mathrm{CO}(700 \pm 200 \mathrm{ppm}), \mathrm{H}_{2} \mathrm{O} \quad(<1000 \mathrm{ppm}$, with an average at $200 \mathrm{ppm}), \mathrm{H}_{2}(20 \mathrm{ppm}), \mathrm{O}_{3}(<0.2 \mathrm{ppm})$ and $\mathrm{CH}_{4}(<50 \mathrm{ppb}$, with an average at $15 \mathrm{ppb})$.

For an atmospheric pressure on Mars of $0.6 \mathrm{kPa}$, the temperature at which the hydrates are stable is $149.3 \mathrm{~K}$ (if SI structure is assumed) or $152.8 \mathrm{~K}$ (if sII structure is assumed). Because winter surface temperature on the south polar cap can reach $148 \mathrm{~K}$, the formation of $\mathrm{CO}_{2}$ dominated clathrate is possible during winter. Because summer temperature is much above $160 \mathrm{~K}$ in most regions of Mars, most of these hydrates dissociate. Nevertheless, stable hydrates can survive during several seasonal cycles at the top of or inside the south $\mathrm{CO}_{2}$ ice polar cap, and transient hydrates can form on seasonal polar caps during winter. So, we can postulate cycles of formation and dissociation of hydrates associated with the winter/summer cycles, and the formation of stable hydrates over long time scales on the south permanent polar cap. 
The case of methane

Methane is a very low concentration gas $(15 \mathrm{ppb})$ and it has no influence on the equilibrium (Pressure, Temperature) curve.

Table 5 reports the fractionation (or abundance fraction following the definition of Thomas et al, 2009) between gas and hydrate, that is the ratio between the molar fraction of a component in the hydrate and the molar ratio of the same component in the gas.

At low Martian temperatures, methane composition in the hydrate structure SI is in the range from $12 \%$ to $18 \%$ (Table 5). Thomas et al (2009) reported a coefficient of $16.6 \%$ in condition similar to ours (that means a very low methane concentration). The models give very similar results. If we assume the structure II to be formed, the methane composition is higher, in the range from $26 \%$ to $35 \%$ (Table 6)

46

But, whatever the value of the abundance fraction (25-33\% for structure II, 12-18\% for structure I), we can observe that methane is rather well encapsulated in the structure compared to nitrogen or argon. As we said before, both gases do not effectively participate into the structure, first because of their low concentration in the gas, but also due to their low affinity with the hydrate structure. So, nitrogen and argon are not affected by the formation and dissociation of hydrate not disturb the hydrate equilibrium, but methane is affected by the formation of hydrate because it 
for nitrogen and argon. So, theoretically, methane in the gas phase is affected by the cycles of formation and dissociation between winter and summer, and its concentration at the poles could be different.

Table 5

60

\section{Discussion}

From a thermodynamical point of view, $\mathrm{CO}_{2} / \mathrm{N}_{2} / \mathrm{Ar} / \mathrm{CH}_{4}$ clathrate hydrates can form on both seasonal polar caps and on the residual south polar cap. At seasonal scale, an upper limit of the amount of $\mathrm{CH}_{4}$ alternately trapped under hydrate form in the seasonal caps can be estimated by assuming that all condensing/ sublimating water results in the formation of hydrate. Knowing that only a fraction of condensing water is involved in hydrate formation, and that existing laboratory experiments suggest that the kinetics of $\mathrm{CO}_{2}$ hydrate formation is slow at low Martian temperature, with time scales potentially several orders of magnitude above 1 Martian year (Falenty et al., 2011), doing so results in a significant overestimation of the part of methane seasonal variation due to hydrate formation/ dissociation. The amount of water exchanged between seasonal polar caps is of the order of $10^{12} \mathrm{~kg}$ per Martian year (Richardson and Wilson, 2002). Using an abundance ratio of $\mathrm{CH}_{4}$ of 0.3 (average value between the abundance ratio in structure II -Table 5- and the abundance ratio in structure I -Table 6-), a $\mathrm{CH}_{4}$ concentration in hydrate three times smaller than in the atmosphere, and assuming that all this water in involved in hydrate formation, the corresponding exchanged mass of methane is $\approx 710^{2} \mathrm{~kg}$. If clathrates are formed during the massive condensation flow of $\mathrm{CO}_{2}$ on the south polar cap during southern winter, the 
latitudes due to the frictional effect of the $\mathrm{CO}_{2}$ flow (Lefèvre and Forget, 2009). The previous value could be therefore underestimated by a similar factor, with a very maximum of the $\mathrm{CH}_{4}$ exchanged mass of 3 tons. The amount of methane in Mars atmosphere is of the order of 100 tons (Geminale et al., 2011). It results that at most $1 \%$, or a few percents (up to $3 \%$ ), of the atmospheric content of methane can be seasonally exchanged between the two hemispheres. The true value is probably much smaller and the effect of the seasonally alternate formation of clathrates on the $\mathrm{CH}_{4}$ atmospheric content is therefore small, if not negligible.

It is thought that there is a net annual transfer of water from the north permanent polar cap to the south permanent polar cap, due to very low temperatures on the south cap, which acts as a trap for water vapor. The net water transfer rate is estimated to be $\sim 10^{11} \mathrm{~kg} / \mathrm{yr}$, that is a thin water ice layer of $1 \mathrm{~mm}$ thickness per year (Richardson and Wilson, 2002). The residence time of water in the south permanent polar cap is large, typically several million years (time since the last obliquity transition, see e. g. Levrard et al., 2004), and this water interacting with $\mathrm{CO}_{2}$ ice can possibly result in the formation of stable $\mathrm{CO}_{2} / \mathrm{N}_{2} / \mathrm{Ar} / \mathrm{CH}_{4}$ clathrate hydrates, progressively buried within the caps. Because of the enhancement of the $\mathrm{CH}_{4}$ mixing ratio by a factor 4-5 during southern winter above the south polar cap, the effective abundance ratio of $\mathrm{CH}_{4}$ with respect to the globally averaged atmospheric $\mathrm{CH}_{4}$ mixing ratio in these hydrates could be slightly larger than 1 (1.2-1.5), with a $\mathrm{CH}_{4} / \mathrm{CO}_{2}$ ratio in the hydrate similar to, or slightly larger than, the atmospheric ratio. Assuming that all condensing water is involved in hydrate formation, the time required to remove the total atmospheric content would is the order of $\sim 300$ years. This value of the $\mathrm{CH}_{4}$ lifetime with respect to hydrate formation on the south permanent polar cap is probably much underestimated, because only a fraction of the incorporated water ice is involved in hydrate formation, and therefore of the same order as the photochemical lifetime of methane (300 yr, Krasnopolsky, 
2006). Because the true lifetime of methane is much shorter (a few months or years, Lefèvre and Forget, 2009), the net removal of methane by hydrate formation on the south polar cap may be considered as a minor sink.

\section{Conclusions}

In this work, we have proposed a set of Kihara parameters to model pure gas clathrate hydrate equilibrium in Martian winter conditions. We validated the model against experimental model and obtained a good correlation, within a few percent in the best case (Ar) and 20-30\% in the worst case, for $\mathrm{CO}_{2}$ and $\mathrm{CH}_{4}$. The model for $\mathrm{N}_{2}$ has not been validated because of the lack of data at very low temperature. Also, we observed an inversion of the stability of the $\mathrm{CO}_{2}$ hydrate which can be probably a structure II in Martian winter conditions, and not a structure I as it is commonly observed at higher temperature.

Then, we did a simulation of the Martian gas hydrate equilibrium and we found that the hydrate can be considered as stable during the winter, and unstable during the summer. Even if methane does not participate actively in the hydrate equilibrium because of its low relative abundance, its concentration in the gas phase may be affected by the hydrate formation. The reason is that the enclathratation of methane in the structure is not negligible (relative abundance of methane in the hydrate is one third to one fourth of its value in the atmosphere). So, the concentration of methane in the atmosphere may be a priori affected by the cycle of formation and dissociation of hydrates between winter and summer if such cycles are existing. 
We estimated an upper limit on the possible seasonal variation of methane generated by a hypothetical alternate formation of hydrates on the seasonal polar caps. This upper limit is a few percent of the atmospheric content of methane and can be considered as negligible. We similarly proposed an upper limit for the lifetime of methane with respect to trapping on the south permanent polar cap through hydrate formation, and found a minimum lifetime of 300 years, of the same order as the photochemical lifetime and much longer than the presumably short lifetime of six months derived from dynamical modelling. These mechanisms are therefore not expected to play a significant role in the present dynamics of Martian methane, although they could have been significant at early times, when the atmosphere contained more methane.

Interestingly, hypothesized clathrate hydrates trapped in the permanent south polar cap could include methane in relative proportions between 0.3 (equilibrium value) and 1.5 (due to frictional enhancement by $\mathrm{CO}_{2}$ condensing flow) times the average global atmospheric ratio. Searching for the spectral signatures of clathrate hydrates on the caps and, if detectable, of inhomogeneities of the $\mathrm{CH}_{4}$ mixing ratio in possible local atmospheric plumes forming during the sublimation of polar hydrate pockets in spectroscopic data from existing (Mars Express, MRO) and future (TGOExomars) missions is clearly an interesting challenge of Mars science and astrobiology.

Acknowledgments: We acknowledge support from CNRS EPOV interdisciplinary program 


\section{References}

Adamson, A.W., Jones, B.R., 1971. Physical Absorption of Vapor on Ice. IV. Carbon dioxide. J. Colloid Interface Sci. 37, 831-835

Atreya, S. K., Mahaffy, R. P., Wong, A., 2006. Methane and related trace species on Mars: Origin, loss, implications for life, and habitability, Planet. Space Sci. 55, 358-369.

Barrer, R.M., and Edge, A.V.J., 1967. Gas Hydrates Containing Argon, Krypton and Xenon: Kinetics and Energetics of Formation and Equilibria. Proc. R. Soc. London, Ser. A., A. 300, 1-24

Chassefière, E., 2009. Metastable methane clathrate particles as a source of methane to the Martian atmosphere, Icarus 204, 137-144.

Chassefière E., Leblanc, F. 2011. Methane release and the carbon cycle on Mars, Planet. Space Sci. 59, 207-217.

Chastain, B. K., Chevrier, V., 2007. Methane clathrate hydrates as a potential source for Martian atmospheric methane, Planet. Space Sci. 55, 1246-1256.

de Forcard, M.R., 1923. Sur les hydrates d'Argon et de Krypton. Comptes rendus de l'académie des Sciences, $355-358$

Deaton, W.M., Frost, E.M., 1946. Gas Hydrates and Their Relation to operation of Natural-Gas Pipelines. U.S., Bur. Mines Monogr. 8, 1-101

Delsemme A.H., Wenger A., 1970. Physical-Chemical penomena in comets -I.Experimental study of snows in a ccometary environment. Planet. Space Sci. 18, 709-715

Falabella, B.J. , 1975. A study of Natural Gas Hydrates, Ph.D. Thesis, University of Massachussetts, Ann Arbor, MA

Falabella, B.J., Vanpee, M., 1974. Experimental Determination of Gas Hydrate Equilibrium below the Ice Point. Ind. Eng. Chem. Fundam.13, 228-231 
Falenty, F., Genov, G., Hansen, T.C., Kuhs, W.F., Salamentin, A.N., 2011. Kinetics of $\mathrm{CO}_{2}$ Hydrate Formation from Water Frost at Low Temperatures: Experimental Results and Theoretical Model, J. Phys. Chem. C. 115, 4022-4032.

Formisano, V., Atreya, S., Encrenaz, T., Ignatiev, N., Giuranna, M., 2004. Detection of methane in the atmosphere of Mars. Science 306, 1758-1761.

Fonti, S., Marzo, G.A. 2010. Mapping the methane on Mars, Astron. Astrophys., 512, A51.

Fray, N, Marboeuf, U., Brissaud, O., Schmidtt, B., 2010. Equilibrium Data of Methane, Carbon Dioxide, and Xenon Clathrate Hydrates below the Freezing Point of Water. Applications to Astrophysical Environments. , J. Chem. Eng. Data 55(11), 5101-5108

Geminale, A., Formisano, V., Sindoni, G., 2011. Mapping methane in Martian atmosphere with PFS-MEX data, Planet. Space Sci. 59, 137-148.

Handa, Y.P., Tse, J.S., 1986, J. Phys. Chem. 23, 5917.

Herri, J.-M. $\square$, Bouchemoua, A., Kwaterski, M., Fezoua, A., Ouabbas, Y., Cameirao, A., 2011. Gas Hydrate Equilibria from $\mathrm{CO} 2-\mathrm{N} 2$ and $\mathrm{CO} 2-\mathrm{CH} 4$ gas mixtures - Experimental studies and Thermodynamic Modelling. Fluid Phase Equilibria 301, 171-190

Holder, G.D., Corbin, G., and Papadopoulos, K.D., 1980. Ind. Eng. Chem. Fundam. 19, 282-286

Jhaveri, J. and Robinson,D.B., 1965. Can. J. Chem. Eng. 43, 75

John, V. T., Holder, G. D., 1982, Journal of Physical Chemistry 86(4), 55-459.

John, V. T. , Papadopoulos, K. D., Holder, G. D., 1985, A generalized model for predicting equilibrium conditions for gas hydrates, AIChE J., 31, 252-259.

Krasnopolsky, V. A., Maillard, J.-P., Owen, T. C., 2004. Detection of methane in the Martian atmosphere: evidence for life?, Icarus 172, 537.

Krasnopolsky, V.A., 2006. Some problems related to the origin of methane on Mars, Icarus 180, 359-367.

Kuhs, W.F., Klapproth, A., Chazallon, 2000. B., Chemical Physics of air clathrate hydrates, in: Physics of Ice-Core Records. Ed. T. Hondoh, Hokkaido University Press, Sapporo, pp 373-392, ISBN 4-8329$0282-2$ 
Larson, S.D., 1955, Phase Studies of the Two Component Carbon Dioxide-Water System Involving the carbon Dioxide Hydrate, Ph.D. Thesis, University of Illinois, Urbana, IL

Lefèvre, F. Forget, F., 2009. Observed variations of methane on Mars unexplained by known atmospheric chemistry and physics, Nature 460, 7256, 720-723.

Levrard, B., Forget, F., Montmessin, F., Laskar, J. 2004. Ice-rich deposits formed at high latitude on Mars by sublimation of unstable equatorial ice during low obliquity, Nature 431, 7012, 1072-1075.

Lyons, J., Manning, C., Nimmo, F., 2005. Formation of methane on Mars by fluid-rock interaction in the crust, Geophys. Res Lett. 32, 13, L13201.1-L13201.4.

Makogon, T., Sloan, E.D., 1995. Phase Equilibria for Methane Hydrate from 190 to 262K. J. Chem. Eng. Data 40,344

Meslin, P.-Y., Gough, R., Lefèvre, F., Forget, F., 2011. Little variability of methane on Mars induced by adsorption in the regolith, Planet. Space Sci. 59, 247-258.

Mehta, A.P., Sloan, E.D., 1996. Improved thermodynamic parameters for prediction of structure H hydrate equilibria, 42(7), 2036-2046

Miller, S.L., Smythe, W.D., 1970. Carbon Dioxide Clathrate In The Martian Ice Cap, Science 170, 531533

Mohammadi, A.H., Richon, D., 2008. Equilibrium Data of Nitrous Oxide and Carbon Dioxide Clathrates Hydrates, J. Chem. Eng. Data 54, 279-281

Mohammadi, A.H., Richon, D., 2010. Ice-Clathrate Hydrate-Gas Equilibria for Air, Oxygen, Nitrogen, Carbon Monoxide, Methane or Ethane + Water System. Ind. Eng. Chem. Res. 49, 3976-3979

Mohammadi, A., Richon, D., 2011. Ice Clathrate Hydrate - Gas Phase Equilibria for Argon + Water and Carbon Dioxide + Water Systems, Ind. Eng. Chem. Res. 50, 11452-11454

Mckoy, V., Sinagoglu, O. J., 1963. Theory of dissociation pressures of some gas hydrates. J Chem. Phys. 38,2946

Mumma, M. J., Villanueva, G. L., Novak, R. E., Hewagama, T., Bonev, B. P., DiSanti, M. A., Mandell, A. M., Smith, D. M., 2009. Strong Release of Methane on Mars in Northern Summer 2003, Science, 323, $1041-1045$ 
Owen, T., K. Biemann, D.R. Rushneck, J.E. Biller, D.W. Howarth, and A.L. LaFleur, 1977. The composition of the atmosphere at the surface of Mars. J. Geophys. Res., 82, 4635-4639

Oze, C., Sharma, M., 2005. Have olivine, will gas : Serpentinization and the abiogenic production of methane on Mars, Geophys. Res. Lett. 32, L10203.

Parrish, W.R., Prausnitz, J. M., 1972. Dissociation pressure of gas hydrates formed by gas mixtures. Ind. Eng. Chem. Process Develop., 11, 26-35

Richardson, M.I., Wilson, R.J., 2002. Investigation of the nature and stability of the Martian seasonal water cycle with a general circulation model, J. Geophys. Res. 107, E5, 5031, 10.1029/2001JE001536.

Saito S., and Kobayashi, R., 1965. AIChE J., 11(1), 96.

Schmitt, B., 1986. La surface de la glace: structure, dynamique et interactions - implications astrophysique. Ph.D. Thesis, University of Grenoble, Grenoble, France

Sloan, E.D., 1998. Clathrate hydrates of natural gases. 2nd Ed. Marcel Decker, New York

Sloan, E.D., Koh, C.A., 2007. Clathrate hydrates of natural gases. 3nd Ed. CRC Press

Sparks, K.A., Tester, J.W., 1992, Intermolecular potential-energy of water clathrates - The inadequacy of the nearest-neigbor approximation, Journal of Physical Chemistry, 96(22), 11022-11029

Tee, L.S. ,Gotoh, S., Stewart, W., 1966. Molecular Parameters for Normal Fluids. The Kihara Potential for Sperical Core, I\&EC Fudamentals, 5(3) 363-367

Thomas, C., Mousis, O., Picaud, S., Ballenegger, V., 2009. Variability of the methane traping in martian subsurface clathrate hydrates. Planetary and Space Science, 57, 42-47,

van Der Waals, J.D., 1959. Clathrate solution. Advances in chemical physic. 2, 1-57

Von Stackelberg, M., 1949. Feste Gashydrate. Die Naturwissenschaften, 36(12), 359-362

Yasuda, K., Ohmura, R., 2008. Phase Equlibrium of Clathrate Hydrates Formed with Methane, Ethane, Propane or Carbon Dioxyde at temperatures below the Freezing Point of Water. J. Chem. Eng. Data, $53,2182-2188$ 
Tables :

Table 1

Structure of SI and SII gas Hydrates

\begin{tabular}{|ccc|c|c|}
\hline \multicolumn{3}{|c|}{} \\
\hline
\end{tabular}

Sloan $(1998$, p. 33)

(2) Variation in distance of oxygen atoms from centre of cages (Sloan, 1998, p. 33).

(3) For ethane hydrate, from (Udachin, 2002).

(4) For tetrahydrofuran hydrate, from Udachin (2002) 
Table 2

Kihara parameters optimized during this work

\begin{tabular}{|ccccc|}
\cline { 2 - 5 } \multicolumn{1}{c|}{} & $\frac{\varepsilon}{k}$ & $a$ & $\sigma$ & \\
\hline $\mathrm{CO}_{2}$ & 178.21 & 0.6805 & 2.873 & This work \\
$\mathrm{CH}_{4}$ & 166.36 & 0.3834 & 3.05 & \\
$\mathrm{~N}_{2}$ & 133.13 & 0.3526 & 3.0993 & \\
$\mathrm{Ar}$ & 174.14 & 0.184 & 2.9434 & \\
\hline $\mathrm{CO}_{2}$ & 171.41 & 0.6805 & 2.9830 & Herri et al, \\
$\mathrm{CH}_{4}$ & 158.71 & 0.3834 & 3.1503 & 2011 \\
$\mathrm{~N}_{2}$ & 138.22 & 0.3526 & 3.0993 & \\
\hline
\end{tabular}

Table 3

Reference state parameters

\begin{tabular}{|l|l|l|l|}
\multicolumn{5}{c}{ Reference state parameters } \\
\hline$\Delta \mu_{\mathrm{w}}^{I-\beta, 0}$ & Unit & Structure I & Structure II \\
\hline$\Delta h_{\mathrm{w}}^{\mathrm{I}-\beta, 0}$ & $\mathrm{~J}$ mol & 1287 & 1068 \\
\hline$\left.\Delta v_{\mathrm{w}}^{\mathrm{L}-\beta}\right|_{T^{0}}$ & $10^{-6} \mathrm{~m}^{3} / \mathrm{mol}$ & 4.5959 & 764 \\
\hline$\Delta c_{p, \mathrm{w}}^{\mathrm{L}-\beta, 0}$ & $\mathrm{~J} /\left(\mathrm{mol} \mathrm{K}^{-1}\right)$ & -38.12 & 4.99644 \\
\hline$b_{p, \mathrm{w}}^{\mathrm{L}-\beta}$ & $\mathrm{J} /\left(\mathrm{mol} \mathrm{K}^{-2}\right)$ & 0.141 & 0.141 \\
\hline
\end{tabular}

$\Delta \mu_{\mathrm{w}}^{\mathrm{L}-\beta, 0}, \Delta h_{\mathrm{w}}^{\mathrm{I}-\beta, 0}:$ Handa and Tse, 1986

$\left.\Delta v_{\mathrm{w}}^{\mathrm{L}-\beta}\right|_{T^{0}}, \Delta c_{p, \mathrm{w}}^{\mathrm{L}-\beta, 0}, b_{p, \mathrm{w}}^{\mathrm{L}-\beta}:$ Sloan, 1998 
Table 4

Equilibirum conditions of pure $\mathrm{CO}_{2}$ and Martian gas hydrates

\begin{tabular}{|c|c|c|c|c|c|c|c|}
\hline \multirow{3}{*}{$\mathrm{T}(\mathrm{K})$} & $\begin{array}{c}\text { Pure } \mathrm{CO}_{2} \\
\text { Hydrate }\end{array}$ & \multicolumn{6}{|c|}{$\begin{array}{c}\mathrm{CO}_{2}-\mathrm{Ar}-\mathrm{N}_{2} \mathrm{Hydrate} \\
\text { Gas composition }\left(0.953 \mathrm{CO}_{2}, 0.026 \mathrm{Ar}, 0.020 \mathrm{~N}_{2}\right)\end{array}$} \\
\hline & \multicolumn{3}{|c|}{ Equilibrium Pressure $(\mathrm{Pa})$} & \multirow[b]{2}{*}{$\theta$} & \multicolumn{3}{|c|}{ Hydrate composition } \\
\hline & SII structure & SIl structure & SI structure & & $\mathrm{CO}_{2}$ & $\mathrm{~N}_{2}\left(\times 10^{3}\right)$ & $\operatorname{Ar}\left(x 10^{3}\right)$ \\
\hline 139 & 96 & 99 & 202 & 0.962 & 0.999 & 0.15 & 0.52 \\
\hline 140 & 111 & 117 & 226 & 0.963 & 0.999 & 0.16 & 0.54 \\
\hline 141 & 129 & 135 & 252 & 0.963 & 0.999 & 0.16 & 0.56 \\
\hline 142 & 147 & 154 & 280 & 0.963 & 0.999 & 0.17 & 0.59 \\
\hline 143 & 169 & 176 & 309 & 0.964 & 0.999 & 0.18 & 0.61 \\
\hline 144 & 192 & 202 & 347 & 0.964 & 0.999 & 0.18 & 0.64 \\
\hline 145 & 219 & 230 & 385 & 0.964 & 0.999 & 0.19 & 0.67 \\
\hline 146 & 249 & 260 & 427 & 0.964 & 0.999 & 0.20 & 0.70 \\
\hline 147 & 283 & 296 & 474 & 0.964 & 0.999 & 0.20 & 0.73 \\
\hline 148 & 321 & 336 & 524 & 0.964 & 0.999 & 0.21 & 0.75 \\
\hline 149 & 362 & 377 & 580 & 0.964 & 0.999 & 0.22 & 0.79 \\
\hline 150 & 410 & 429 & 640 & 0.965 & 0.999 & 0.23 & 0.82 \\
\hline 151 & 462 & 484 & 708 & 0.965 & 0.999 & 0.23 & 0.85 \\
\hline 152 & 519 & 545 & 781 & 0.965 & 0.999 & 0.24 & 0.88 \\
\hline 153 & 585 & 613 & 860 & 0.965 & 0.999 & 0.25 & 0.91 \\
\hline 154 & 657 & 688 & 946 & 0.965 & 0.999 & 0.26 & 0.95 \\
\hline 155 & 736 & 771 & 1039 & 0.965 & 0.999 & 0.26 & 0.98 \\
\hline 156 & 824 & 863 & 1145 & 0.965 & 0.999 & 0.27 & 1.02 \\
\hline 157 & 921 & 964 & 1255 & 0.965 & 0.999 & 0.28 & 1.06 \\
\hline 158 & 1027 & 1064 & 1373 & 0.965 & 0.999 & 0.29 & 1.09 \\
\hline 159 & 1145 & 1198 & 1511 & 0.965 & 0.999 & 0.30 & 1.13 \\
\hline 160 & 1274 & 1333 & 1654 & 0.965 & 0.999 & 0.31 & 1.17 \\
\hline 161 & 1410 & 1481 & 1809 & 0.965 & 0.998 & 0.32 & 1.21 \\
\hline
\end{tabular}


Table 5

Abundance fraction of component in hydrate versus component in gas

SII is supposed

\begin{tabular}{|c|c|c|c|c|c|}
\hline \multicolumn{2}{|c|}{$\begin{array}{l}\text { Equilibrium condition } \\
\text { Gas }=95,3 \% \mathrm{CO}_{2}, 2 \% \mathrm{Ar} \\
2.7 \% \mathrm{~N}_{2}, 15 \mathrm{ppb} \mathrm{CH}_{4}\end{array}$} & \multicolumn{4}{|c|}{$\begin{array}{l}\text { Abundance ration }=x i / f i \\
x i: \text { composition of } i \text { in the hydrate } \\
\mathrm{fi}: \text { composition of } i \text { in the gas } \\
\text { SIl is supposed }\end{array}$} \\
\hline $\mathrm{T}(\mathrm{K})$ & $\mathrm{P}(\mathrm{kPa})$ & $\mathrm{CO}_{2}$ & $\mathrm{~N}_{2}$ & $\mathrm{Ar}$ & $\mathrm{CH}_{4}$ \\
\hline 139 & 99.0 & 1.048 & 0.008 & 0.020 & 0.262 \\
\hline 140 & 117.3 & 1.048 & 0.008 & 0.021 & 0.266 \\
\hline 141 & 134.7 & 1.048 & 0.008 & 0.022 & 0.270 \\
\hline 142 & 154.4 & 1.047 & 0.008 & 0.023 & 0.274 \\
\hline 143 & 176.3 & 1.047 & 0.009 & 0.024 & 0.278 \\
\hline 144 & 201.6 & 1.047 & 0.009 & 0.025 & 0.282 \\
\hline 145 & 229.6 & 1.047 & 0.009 & 0.026 & 0.286 \\
\hline 146 & 259.7 & 1.047 & 0.010 & 0.027 & 0.291 \\
\hline 147 & 296.5 & 1.047 & 0.010 & 0.028 & 0.295 \\
\hline 148 & 335.5 & 1.047 & 0.011 & 0.029 & 0.299 \\
\hline 149 & 377.2 & 1.047 & 0.011 & 0.030 & 0.303 \\
\hline 150 & 429.4 & 1.047 & 0.011 & 0.031 & 0.307 \\
\hline 151 & 484.3 & 1.047 & 0.012 & 0.033 & 0.311 \\
\hline 152 & 545.4 & 1.047 & 0.012 & 0.034 & 0.315 \\
\hline 153 & 613.0 & 1.047 & 0.012 & 0.035 & 0.319 \\
\hline 154 & 688.0 & 1.047 & 0.013 & 0.036 & 0.323 \\
\hline 155 & 771.1 & 1.047 & 0.013 & 0.038 & 0.327 \\
\hline 156 & 862.7 & 1.047 & 0.014 & 0.039 & 0.331 \\
\hline 157 & 964.0 & 1.047 & 0.014 & 0.041 & 0.335 \\
\hline 158 & 1063.7 & 1.047 & 0.014 & 0.042 & 0.339 \\
\hline 159 & 1198.2 & 1.047 & 0.015 & 0.044 & 0.343 \\
\hline 160 & 1332.7 & 1.047 & 0.015 & 0.045 & 0.347 \\
\hline 161 & 1481.2 & 1.047 & 0.016 & 0.047 & 0.351 \\
\hline
\end{tabular}


Table 6

Abundance fraction of component in hydrate versus component in gas SI is supposed

\begin{tabular}{|c|c|c|c|c|c|}
\hline \multicolumn{2}{|c|}{$\begin{array}{c}\text { Equilibrium condition } \\
\text { Gas }=95,3 \% \mathrm{CO}_{2}, 2 \% \mathrm{Ar} \text {, } \\
2.7 \% \mathrm{~N}_{2}, 15 \mathrm{ppb} \mathrm{CH}_{4}\end{array}$} & \multicolumn{4}{|c|}{$\begin{array}{l}\text { Abundance ration }=x i / f i \\
x i \text { : composition of } \mathrm{i} \text { in the hydrate } \\
\mathrm{fi} \text { : composition of } \mathrm{i} \text { in the gas } \\
\mathrm{SI} \text { is supposed }\end{array}$} \\
\hline $\mathrm{T}(\mathrm{K})$ & $\mathrm{P}(\mathrm{kPa})$ & $\mathrm{CO}_{2}$ & $\mathrm{~N}_{2}$ & $\mathrm{Ar}$ & $\mathrm{CH}_{4}$ \\
\hline 139 & 202.2 & 1.048 & 0.003 & 0.005 & 0.126 \\
\hline 140 & 225.7 & 1.048 & 0.004 & 0.005 & 0.129 \\
\hline 141 & 251.6 & 1.048 & 0.004 & 0.006 & 0.131 \\
\hline 142 & 279.8 & 1.048 & 0.004 & 0.006 & 0.134 \\
\hline 143 & 309.2 & 1.048 & 0.004 & 0.006 & 0.137 \\
\hline 144 & 347.1 & 1.048 & 0.004 & 0.006 & 0.139 \\
\hline 145 & 385.4 & 1.048 & 0.005 & 0.007 & 0.142 \\
\hline 146 & 427.5 & 1.048 & 0.005 & 0.007 & 0.144 \\
\hline 147 & 473.9 & 1.048 & 0.005 & 0.007 & 0.147 \\
\hline 148 & 524.1 & 1.048 & 0.005 & 0.008 & 0.149 \\
\hline 149 & 579.8 & 1.048 & 0.005 & 0.008 & 0.152 \\
\hline 150 & 640.1 & 1.048 & 0.006 & 0.009 & 0.155 \\
\hline 151 & 708.1 & 1.048 & 0.006 & 0.009 & 0.157 \\
\hline 152 & 780.8 & 1.048 & 0.006 & 0.009 & 0.160 \\
\hline 153 & 860.4 & 1.048 & 0.006 & 0.010 & 0.163 \\
\hline 154 & 946.2 & 1.048 & 0.006 & 0.010 & 0.165 \\
\hline 155 & 1039.0 & 1.048 & 0.007 & 0.011 & 0.168 \\
\hline 156 & 1144.9 & 1.048 & 0.007 & 0.011 & 0.171 \\
\hline 157 & 1255.4 & 1.048 & 0.007 & 0.012 & 0.173 \\
\hline 158 & 1372.9 & 1.048 & 0.008 & 0.012 & 0.176 \\
\hline 159 & 1510.5 & 1.048 & 0.008 & 0.013 & 0.179 \\
\hline 160 & 1654.3 & 1.048 & 0.008 & 0.013 & 0.181 \\
\hline 161 & 1808.9 & 1.048 & 0.008 & 0.014 & 0.184 \\
\hline
\end{tabular}


Figure captions :

Figure 1: Deviation between experimental equilibrium data of pure $\mathrm{CO}_{2}$ hydrate and model versus $\varepsilon / k$ and $\sigma . a$ value is taken from Table 2. Data are taken fromYasuda and Ohmura (2008), Adisasmito et al. (1991), Falabella (1975), Miller and Smythe (1970) which cover a range of temperature from $151.52 \mathrm{~K}$ to $282.9 \mathrm{~K}$ and a pressure range from $0.535 \mathrm{kPa}$ to $4370 \mathrm{kPa}$.

Figure 2: $\varepsilon / k$ versus $\sigma$ at the minimum deviation with experimental data. $a$ value is taken from Table 2. Pressure and temperature equilibrium data for $\mathrm{CO}_{2}$ hydrate are taken fromYasuda and Ohmura (2008), Adisasmito et al. (1991), Falabella (1975), Miller and Smythe (1970) which cover a range of temperature from $151.52 \mathrm{~K}$ to $282.9 \mathrm{~K}$ and a pressure range from $0.535 \mathrm{kPa}$ to $4370 \mathrm{kPa}$.

Figure 3 : Equilibrium pressure of pure $\mathrm{CO}_{2}$ gas hydrate at low temperature down to the Martian winter Martian conditions $(148 \mathrm{~K} \pm 10 \mathrm{~K})$

Figure 4: $\varepsilon / k$ versus $\sigma$ at the minimum deviation with experimental data. $a$ value is taken from Table 2. Pressure and temperature equilibrium data for $\mathrm{CH}_{4}$ hydrate are taken from Fray et al (2010), Yasuda and Ohmura (2008), Adisasmito et al. (1991) which cover a range of temperature from 145.75 to $286.4 \mathrm{~K}$ and a pressure range from $2.4 \mathrm{kPa}$ to $10570 \mathrm{kPa}$

Figure 5 : Equilibrium pressure of pure $\mathrm{CH} 4$ gas hydrate at low temperature down to the Martian winter Martian conditions $(148 \mathrm{~K} \pm 5 \mathrm{~K})$

Figure 6 : Equilibrium pressure of pure Argon gas hydrate at low temperature (283-263K and 150-90K) 
Figure 7 : Equilibrium pressure of pure Nitrogen gas hydrate in a limited range of temperature (273 down to $250 \mathrm{~K})$ 